\title{
CHALLENGING THE INVISIBILITY OF MOBILE CULTURES REMOTE SENSING, ENVIRONMENT AND ARCHAEOLOGY IN THE NEAR EAST
}

\author{
M. Silver ${ }^{1}$, M. Törmä ${ }^{2}$ K. Silver ${ }^{3}$, M. Nuñez ${ }^{1}$ J. Okkonen ${ }^{1}$
}

${ }^{1}$ University of Oulu, Pentti Kaiteran katu 1, 90014 Oulu, Finland - minna.silver@helsinki.fi

${ }^{2}$ Aalto University, Finland, ${ }^{3}$ Independent researcher

\begin{abstract}
KEY WORDS: Remote sensing, satellite imagery, environment, archaeology, mobile cultures, GIS, landscape modeling
\end{abstract}
\begin{abstract}
Remote sensing has provided a modern wider perspective to approach the earth with its various environments and impact of humans by prospecting previously unknown frontiers of human life. The traces of mobile groups are archaeologically often more difficult to detect than those of the sedentary ones, but new approaches and methods have changed and enhanced the ways to extract archaeological information of hunter-gatherers and pastoral nomads. Remote sensing, for example, provides alternative views from above and better visibility in a larger scale, especially with high resolution solutions, than on the ground to trace sites. Mobile people have become more visible in archaeology, and therefore their importance in the development of human cultures has received more focus and understanding. This paper will focus on the use of remote sensing in the archaeological study of mobile cultures and their environments in the Near East. Various examples of techniques and site types will be discussed, and the suitability of applications will be considered based on the studies by Finnish and Finnish-Swedish projects in the Near East. We will provide examples of applications and emphasize the importance of empirical approaches in studying archaeological evidence by remote sensing. GPS coordinate points have served as the basis of our field survey and mapping. From the image-based data we shall deal with aerial photographs, CORONA satellite photographs, Landsat, SPOT, QuickBird and GeoEye satellite images. From the range-based data we shall discuss X-SAR Shuttle Mission 2000 and ASTER-DEM data, but LiDAR and geophysical devices will only be briefly considered.
\end{abstract}

\section{INTRODUCTION}

Archaeology of mobility has particular challenges, because of the ephemeral nature of many types of remains hunter-gatherers andpastoral nomads leave behind. (See, e.g., Wendrich and Barnard, 2008). This does not mean that all the remains have been lost but that there are challenges to detect the preserved ones. During the past decades new technologies and methods of inquiries have enhanced prospecting and studying the mobile cultures (see Silver, 2016b). They have provided new ways to extract information of these cultures and make them more visible in the archaeological record. Remote sensing, for example, has provided large scale views and new devices, data, programs and software attaining better resolutions for prospecting unknown frontiers and signs of human life and sites of dwellings. Actually, one of the first great discoveries by satellite archaeology was Ubar, a caravan city of mobile people in Oman ( see Lem, 2017).

Archaeology provides the longest perspective in studying human cultural impact on earth. It opens a possibility to a long-term view in approaching the relation of humans with their environment. With remote sensing studies the modern technological world meets the ancient one. The Near East forms a bridge between different continents and has provided the evidence of movements of people over the millennia. By using aerial photography, satellite images and radar data we can zoom in and study the environment of the region and traces of humans.

As far as the time scale of the human way of life on earth is concerned, its longest period pertains to mobility, i.e., huntergatherers and later pastoral nomads. They represent cultures that have had an intimate relationship with the environment.
Identifying remains of mobile cultures is important because mobility has governed the human past much longer than the sedentary ways of life. Today archaeology of mobility also offers avenues for studying migrations and the material signs they might leave behind (see, e. g., Burmeister 2000; Rouse, 1986). From the beginning the humans participated in great diasporas that can be nowadays tracked by DNA (Cavalli-Sforza, 1996; Oppenheimer, 2004).

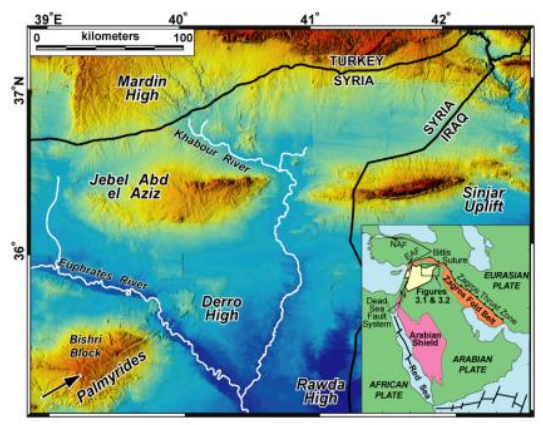

Figure 1. A topographic map showing the Bishri block in Central Syria in the left corner below. Courtesy: M. Baranzangi

This paper brings up different data sources in remote sensing and how they can be applied in studying mobile cultures. The benefits of remote sensing also lie in the fact that remote sensing provides non-invasive methods. The Finnish project SYGIS prospected by old aerial photographs and recent satellite imagery remains of hunter-gathers and pastoral nomads in the mountainous region of Jebel Bishri belonging to the Palmyrides in Central Syria (Fig. 1) in a desert-steppe environment in 1999/2000-2010 (see Lönnqvist 
et al., 2011), and such prospecting can still be carried out from a desktop despite of the civil war in Syria.

But observing archaeological sites and structures by remote sensing from air and space needs empirical testing on the ground either by surveying or excavating to secure the right understanding of the nature of remains. SYGIS carried out field surveys on the ground in Syria, also using geophysical devices reveal subsoil features but requires excavation for the identification of remains. There have been misinterpretations in the past on the nature and age of discoveries by only making conclusions based on remote sensing. The ground survey or an excavation can finally empirically bring confirmation of the nature and age of the site.

\section{RECORDING COORDINATES}

For archaeology the knowledge of the location of a site or a structure is of utmost importance. It is an identifier of a site. Coordinate information should be collected in all archaeological studies, as coordinates are scientific and unambigious parameters providing exact information of a site location on earth. UNESCO, for example, publishes such geographic coordinates as the central coordinate of the site and boundary points of its visible or otherwise known borders (www.whc.unesco.org: document coordinates).

Obtaining coordinate information is the first step in the recording and protection of a site. It is also needed for GIS (Geographic Information Systems) (see Lönnqvist and Stefanakis, 2009) that was used in the Finnish project SYGIS: the UTM coordinate system was applied in the project. GPS (Global Positioning System) was primarily used for recording the location of archaeological sites and structures on the ground. GPS was also used on the ground to collect waypoints. For Landsat-7 ETM images we also still needed to collect control points with a GPS on the ground in order to orthorectify the images, and then the panchromatic channel of Landsat-7 providing $15 \mathrm{~m}$ spatial resolution was used for mapping with MapSheets Express software (Figure 2). It offered means for prospection and map sites more in detail than the cartographic data that was available. (Lönnqvist et al., 2011)

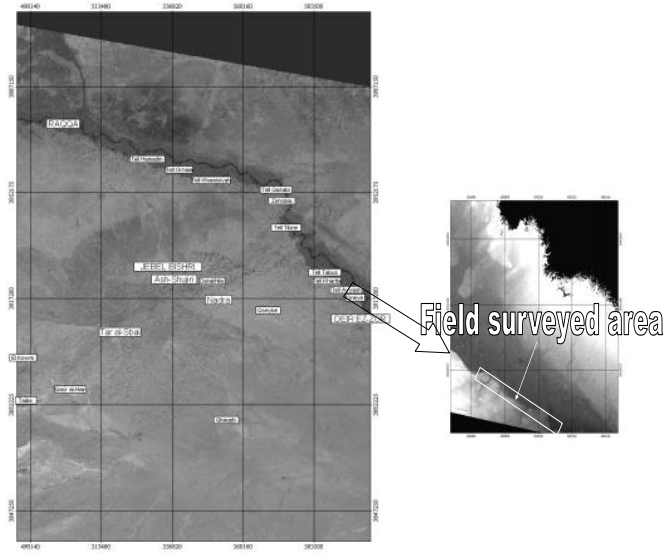

Figure 2. Mapping some major sites using the panchromatic channel of Landsat-7 ETM and MapSheets Express software as well as locating a survey area at the river edge with ASTERDEM data. Mapping by M. Lönnqvist (present Silver) 2006.
Coordinates can also be attained from satellite image data. In a period of the past decade GoogleEarth enhanced its spatial resolution and offered more possibilities to record coordinates, but the image data that it offers is not comparable to tesselated satellite images that bear huge amount of numeric data and can be used for various types of GIS (Geographic Information Systems) analyses. Declassified CORONA satellite photographs (when digitized provide up to $1.8 \mathrm{~m}$ in spatial resolution) was the cheapest alternative for using higher resolution satellite data sources thanks to their release to open market, and we used them since 2003. They needed digitizing and to be rectified to be used in a particular coordinate system. But nowadays one can acquire them readily digitized.

However, the satellite images such as QuickBird images $(0.6 \mathrm{~m}$ spatial resolution) and GeoEye images $(0.46 \mathrm{~m}$ spatial resolution in panchromatic channel), offer the highest spatial resolution that has been available in commercial market. We have used all these satellite data sources in various ways in order to find answers to scientific questions both in Syria and in Turkey (see Lönnqvist et al., 2011; Silver et al., 2017). Here we only deal with the questions that are pertaining to hunter-gatherers and pastoral nomads respectively. We used geophysical devices such as Ground Penetrating Radar (GPR) (Lönnqvist et al. 2011) studying alluvial terraces for grazing ground and tomb sites of pastoral nomads.

Three-dimensional recording ( $\mathrm{x}, \mathrm{y}$ and $\mathrm{z}$ ) has been used in archaeology over a hundred years. Stereophotographs brought three-dimensional ways to document sites already in the end of the $19^{\text {th }}$ century, also in the Near East (Silver, 2016). With modern technologies SYGIS continued in recording, documenting and modeling sites and landscapes in 3D (Lönnqvist et al., 2012). Nowadays LiDAR (Light Detection and Ranging technique), terrestrial laser scanners and 3D cameras can be used, if the budget allows, but they were not available yet or not in our reach nearly twenty years ago. SYGIS applied a total station for recording and documenting sites and small finds in detail (Fig. 3). Photographing was carried out using both a digital and analogue cameras for documentation in situ. Site sheets were kept for recording. (Lönnqvist et al., 2011).

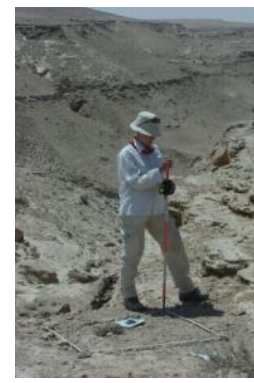

Figure 3. Detailed recording of Palaeolithic workshops with total station and a prism at Tar al-Sbai on Jebel Bishri. Photo: SYGIS 2000 .

\section{REMOTE SENSING ENVIRONMENTS OF THE ANCIENTS}

As remote sensing by aerial photographs, satellite images and radar data such as included in LiDAR opens an access to visibility from above, these data enable approaches on a larger scale. 
Therefore, the data sources are also used for cartographic purposes. Satellite images provide information of biotic patterning to evaluate resource bases for human living, the information that can be matched with topographic and sedimentary data. This data can be used in for prospecting and planning a ground survey or analysing site locations. (Butzer, 1982, 8). Both hunter-gatherers and pastoral nomads have been dependant in their lifestyle and movement on seasonality.

Especially the areas such as steppe and desert regions, typical for the Near East, are arenas for hunter-gatherers and pastoral nomads. They also are favourable environments for studies and analyses by satellite imagery because there are no thick vegetation covers or cloudy conditions for much of the year. LiDAR can reveal sites and structures under vegetation, even in wooded areas (Silver, 2016a). Nowadays, however, there are a number of principles in remote sensing to distinguish vegetation patterns that indicate archaeological sites (Brooks and Johannes, 1990, 142152). For example, different seasons of the year and times of a day provide varied information in aerial photographs and satellite imagery, such as features of ancient sites in different day-lights or potential for land use such as grazing. We shall in due course discuss the application of such an approach to study grazing potential in steppe areas.

Jebel Bishri is a mountainous area of contrasts as it is steppedesert receiving less than $200 \mathrm{~mm}$ annual rainfall. The area is limited and therefore associated with the Euphrates river valley, and the subsistence economies are divided according to the environment. During the Pleistocene the climate of the region was obviously less arid and the landscape more savannah-type, but the trees have disappeared apart from some small favourable pockets and plantations. However, a continuous forest cover never reached the area during the Holocene. The steppe-desert environment provides opportunities for pastoral nomadism, and the river valley with its irrigation systems for sedentary life and agriculture. (Lönnqvist et al., 2011).

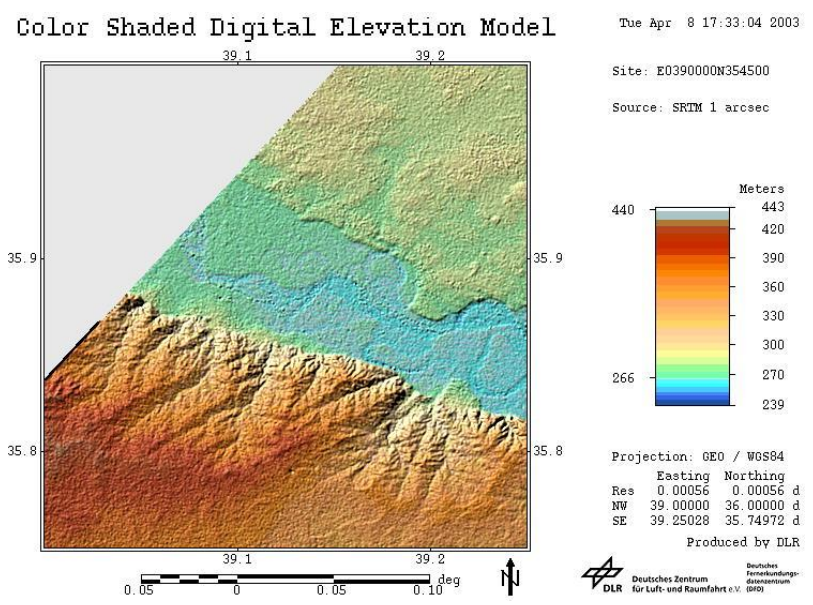

Figure 4. DEM tile from X-SAR shuttle mission 2000 showing parts of Jebel Bishri and the Euphrates river valley. The data was provided German Aerospace Centre.
We have used Landsat-7 ETM and SPOT satellite imagery for environmental studies. Landsat-7 was also used for landscape modeling and cluster analyses that reveal the contrast of the environment and particular features. Radar data from X-SAR Shuttle Mission 2000 was applied to create landscape models by fusing Landssat-7 ETM image data. Radar data was received from the German Aerospace Centre in DEM tiles as SYGIS was accepted into NASA's world monitoring program in 1999. That has also offered possibilities to carry out visibility analyses from Tar al-Sbai on Jebel Bishri occupied both by prehistoric huntergatherers, and pastoral nomads that lived during the prehistoric and historic times in the area. (Lönnqvist et al., 2011)

A palaeolake became detectable on Jebel Bishri by executing cluster analysis with Landsat-7, although the lake was initially detected on the ground in 2004. Several prehistoric sites were recorded on the shores of the lake. (Lönnqvist et al., 2011, 109)

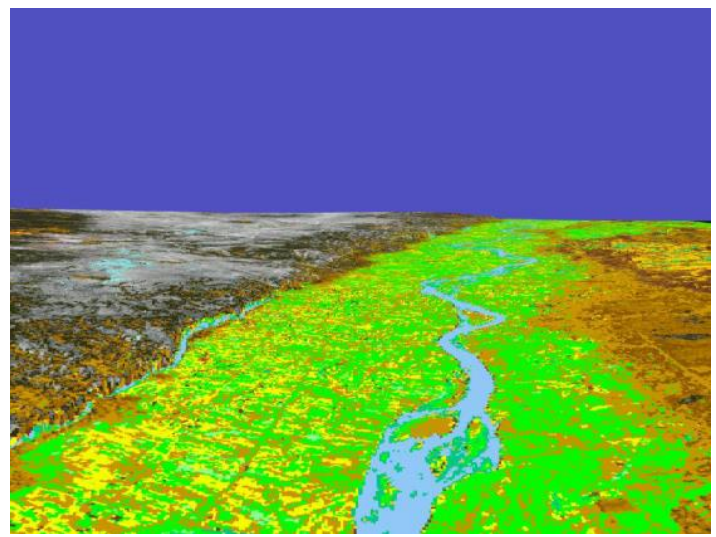

Figure 5. A landscape model showing the Euphrates river valley and Jebel Bishri in Syria produced by fusing X-SAR shuttle mission 2000 DEM data with Landsat-7 ETM image data. Constructed by M. Törmä 2003

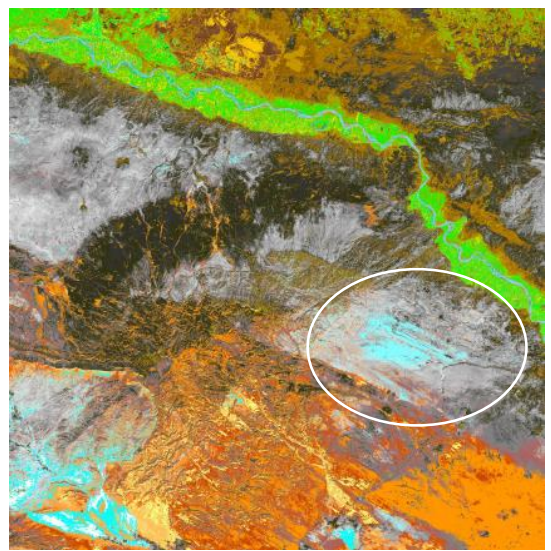

Figure 6. The cluster analysis of the vegetation cover of Jebel Bishri carried out by using Landsat-7 ETM image. The palaeolake area is encircled in white. Analysis by M. Törmä 2004.

River channel changes of the Euphrates were also analysed using CORONA satellite photographs and Landsat images from various years over decades. It is possible that some ancient sites have 
submerged under silts. However, we detected several prehistoric sites on the river terraces (Lönnqvist et al., 2007, 465-470).

It needs to be stated that the sedimentation in desert and steppe areas is relatively slow, and sites can sustain on the surface for thousands of years. We observed this at prehistoric sites. Workshops for tools that were tens of thousands of years old were left behind as if they had been left yesterday. But, if subsoil studies are applied, remote sensing by geophysical devices can be used in prospecting and surveying to detect walls, house floors, pits, tombs, embankments, ditches and roads (Butzer, 1981, 159). For searching pastoral nomadic sites metal detectors can also be used. Tent sites often include such material.

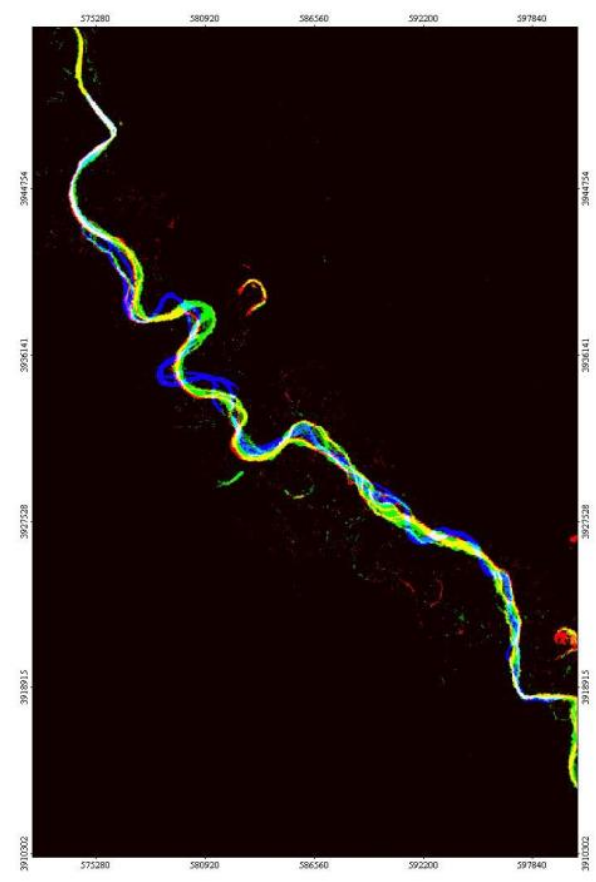

Figure 7. Euphrates channel changes mapped from various satellite images by M. Törmä 2007

Drought increases mobility both among hunter-gatherers (Bird and Bird, 2005, 85) and pastoral nomads. We have studied the effect of desertification by analysing the movement of the desert line using satellite imagery from various. The large veil of sand had expanded significantly between 1990 and 1999 due to increased desertification that has affected the livelihood of pastoralists. (Lönnqvist et al., 2010, 2011).

\section{SITES OF HUNTER-GATHERERS}

Hunting and gathering is the earliest mode of human life and has been present since the Palaeolithic times. There are also huntergathers in present-day native tribes in different parts of the world. The sites that represent the hunter-gatherer phase especially create a challenge for detection by aerial photographing and satellite image prospecting as they do not provide enough resolution to distinguish open-air sites and the dispersion of small tools on the ground. But in the case of the autonomous vehicles, such as drones, aerial photographs and LiDAR can even reach the needed resolutions.
For example, the areas between Jebel Bishri and El Kowm are littered with Palaeolithic tools (Fig. 8). This, however, opens a window to a time scale that we are dealing with. El Kowm is an oasis that has provided finds going back to one million years, and the tools in the piedmonts and valleys are mainly from the Middle Palaeolithic period and represent life in tens of thousands of years. (See Lönnqvist et al., 2012). Beside tools or other small finds rock paintings and drawings are not detectable even with high resolution satellite imagery.

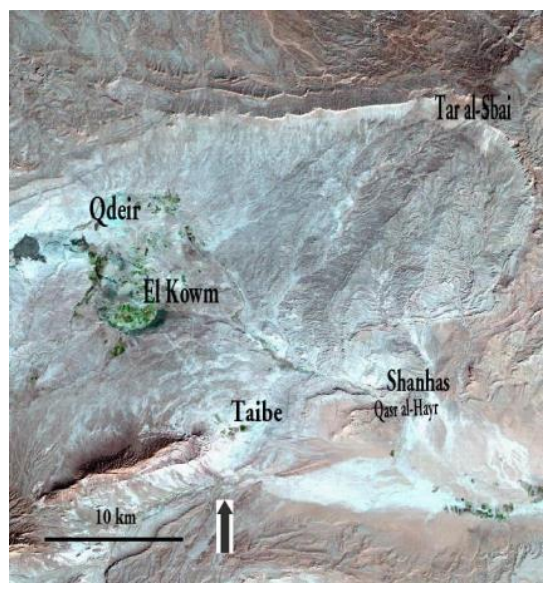

Figure 8. The oasis of El/Al Kowm on the western piedmont of Jebel Bishri and Tar al-Sbai, a semi-circular escarpment of the mountain visible in Landsat-7 ETM. CEurImage. Mapping by M. Lönnqvist (present Silver) 2009.

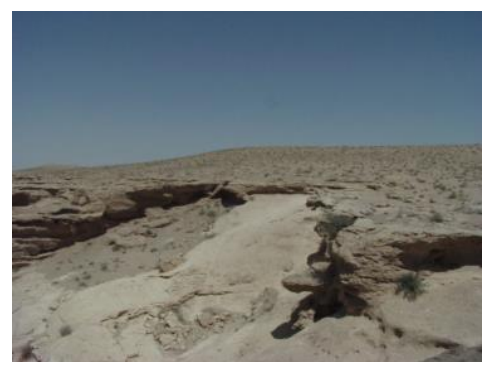

Figure 9. Collapsed Palaeolithic abris at Jebel Bishri. Photo: J.-P. Matar 2000.

The kinds of remains of hunter-gatherers that remote sensing with aerial photographs and satellite imagery can be traced consist of rock shelters, hut bases and kites (large animal traps used for gazelle hunting). Those can be detected in the regions of Jebel Bishri. Rock shelters can be assumed from the shapes of mountain edges, and their relation to known prehistoric sites like El Kowm in our case. Tar al-Sbai is a semi-circular escarpment of Jebel Bishri situated in its western side. We were able to experimentally confirm that there indeed are Paleolithic abris the roof of which have collapsed due to heavy erosion in the region (Fig. 9). On the ground we also found a number of crescentic hunting blinds (Figs. 10 and 11) constructed of field stones at the edge of the mountain. The area offered great visibility to the plains and enabled observance of gazelle movements. All the identified sites were recorded by a total station on the ground. From here we carried out the mentioned visibility analyses to the plains and have 
discussed the landscape models elsewhere (Lönnqvist et al., 2012).

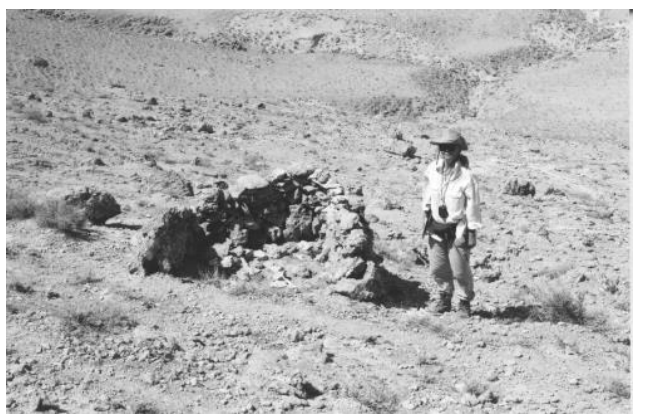

Figure 10. A hunter's blind. Photo: M. Stout Whiting 2000.
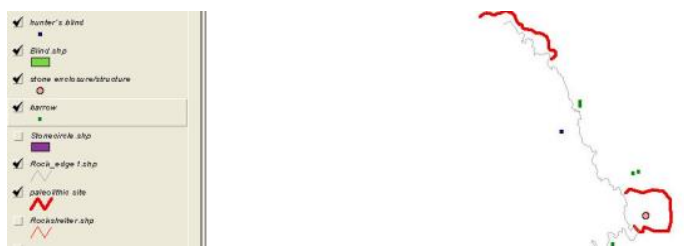

Figure 11. Recording Paleolithic abri sites and hunters' blinds at Tar al-Sbai using a tachaeometre. Measurements by M. Saario and Donald Lillqvist 2000, computer mapping by J. Okkonen.

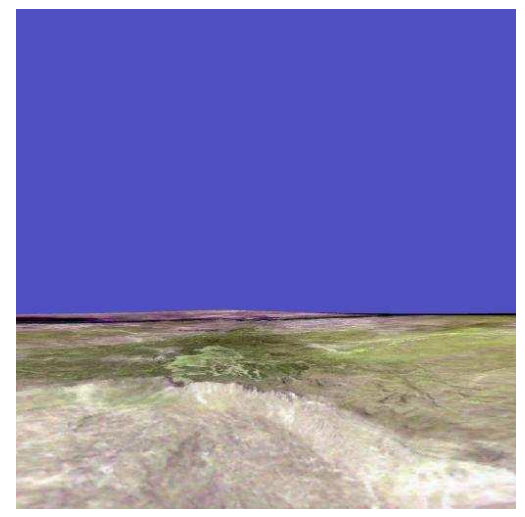

Figure 12. 3D scene of mosaic of Landsat-4 MSS images 172/35 and 36 taken 12.7.1983, channels 574 from south to north at Tar al-Sbai. Constructed by M. Törmä 2006.

Hut bases could be recognized by aerial photographs and satellite images with high spatial resolution. This we have noticed while carrying out and finding possibilities to detect those remains with the help of satellite imagery. GoogleEarth can be used for initial prospecting, but, as mentioned, for GIS analyses it opens limited possibilities. Our personal studies have provided information concerning the application of QuickBird. Spatial resolution of QuickBird $(0.6 \mathrm{~m})$ and nowadays GeoEye $(0.46 \mathrm{~m}$ in panchromatic channel) provide enough spatial resolution to study structures such as hut bases (see Lönnqvist et al., 2011; Silver et al., 2017).

There are also exceptions like natural monuments and temples of hunter-gathers that are known to be more visible than regular sites.
For example, Göbekli Tepe, situated in southeastern Turkey close to the city of Urfa, is an imposing structure of hunter-gatherers inscribed into the UNESCO World Heritage Sites. It is the site of the so-called world's oldest temple that Klaus Schmidt's excavations discovered in 1995 based on earlier surveys. The site dattes back to the Early Neolithic period (the $10^{\text {th }}$ and $9^{\text {th }}$ millennia $\mathrm{BC})$ and has been a challenge for restoration and conservation. (Schmidt, 2012). New subsoil evidence of extra curvilinear enclosures have been identified by remote sensing at site using geophysical devices (Dietrich et al., 2012). In addition, an aboriginal natural monument of Uluru-Kata Tjuta in Australia is one of the exceptions of hunter-gatherer sites in its size. It is also a UNESCO World Heritage Site, and an information system has been developed for it using aerial images of the site (courtesy of the information from C. Ogleby 2008).

\section{SITES OF PASTORAL NOMADS}

To the pastoral technocomplex Southwest-Asian Arid Zone Juris Zarins (1992) has included also kites and such structures as cairns/tumuli and stone circles of various kinds. We recorded cairns/tumuli and stone circles that could be detected on QuickBird images, and surveyed a number of such structures on the ground. GPR studies were also carried out to trace pastoral tombs (Fig. 13) Kites were used in the Stone Age, but also pastoralists have been using them up until recent centuries (Crassard et al., 2014). Jebel Bishri is especially associated with gazelle routes and such traps exist in the local pastoral nomadic environment. In addition, we could like to add wells that can also be included in the pastoral technocomplex and for which we made distribution maps (Lönnqvist et al., 2011).

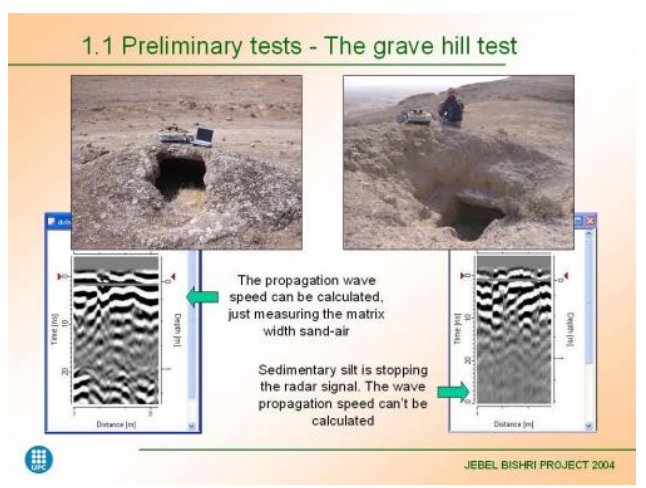

Figure 13. Studying tumuli of pastoral nomads on Jebel Bishri by GPR. Analyses by J. Pedrez-Rodes.

There is and has existed different degrees of nomadism among the pastoralists living in the region: some have been more nomadic than the others. Evidence of year-round mobility was detected among some pastoralists in the mountain and its piedmont plateaus. However, generally semi-nomadism and semi-sedentary pastoralism, also the latter related to transhumant pastoralism, are typical modes of nomadism in the region. Transhumance is vertical nomadism between high- and lowlands. (See Khazanov, 1994; Lönnqvist, 2014).

Textual evidence from the cuneiform sources associates Jebel Bishri with pastoral nomads and tribal people. In the Bronze Age cuneiform sources they are identified as Amorites (3rd to 2nd 
millennium $\mathrm{BC}$ ) and in the Iron Age (late 2nd millennium to 1st millennium BC) as Arameans whose existence (see the references in Lönnqvist et al., 2011) continued to be known in the Roman period. Still Aramaic minorities, also known as Syriac people, are known especially in Syria and Turkey.

But the Arab Bedouins came into the picture from the Iron Age, and they still continue to live in the Jebel Bishri region and the Syrian Desert. Their ways of lives have been recorded over a few centuries (see, e.g., Bell, 1908; Lewis 1987) and also studied by ethnoarchaeological means as well. Present-day Bedouin tents can be detected by aerial photographs (see, e.g., Lewis, 1987, 132) as well as high resolution satellite imagery and LiDAR. We studied several sites with CORONA satellite photography. Such information can be used for ethnoarchaeological studies of pastoral nomadism and finding signs of sedentarization studying the village plans that follow the former tent camps in their layouts. (Lönnqvist et al., 2009, 2011)

\section{SITE CATCHMENT ANALYSES}

The maximum period livestock can be without water in the summer season is approximately three days for goats/sheep, four days for donkeys and twelve days for camels (Heathcote, 1983, 93-94). There have been studies of the spatial use of grazing grounds and tribal territories in archaeology (Chang, 2005). Site catchment analyses were originally carried out for hunter-gatherer sites, but we applied this GIS analysis to grazing grounds (Lönnqvist et al., 2011).

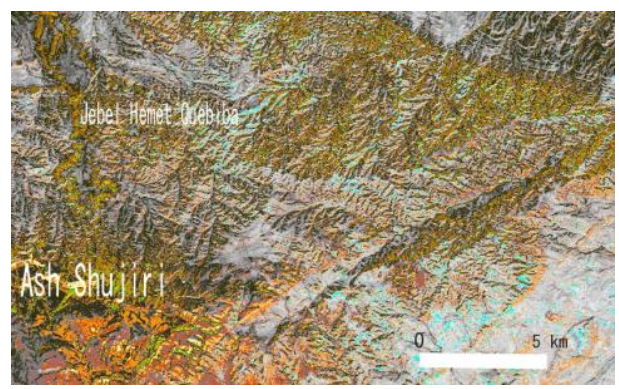

Figure 14. Zooming in on the study area interpreted with a cluster analysis on the Landsat-7 ETM at the village of Ash-Shujiri on Jebel Bishri. Grazing potential in this area is clearly visible in green areas. Cluster analysis by M. Törmä 2010 .

We studied the potential for grazing on Jebel Bishri by cluster analyses (Fig. 14). The Landsat MSS-, TM- and ETM-images were clustered into 30-60 clusters using k-means algorithm (Richards, 1993). The clusters were interpreted by comparing them to satellite images and then determining the most likely land cover type. The grazing potential on the mountain was very high in the winter months compared to the summer and autumn time before the rains. This has apparently affected the transhumance of the area, so that during summers the pastoralists move to the river valley and the Jezira (the so-called island between the Euphrates and the Tigris).

We used QuickBird satellite image data in determining the locations of ancient corrals, animal pens, in relation to the environment and available grazing grounds (Fig. 15). In this study QuickBird satellite image data from the central district of Jebel
Bishri covering $8 \mathrm{~km} \times 8 \mathrm{~km}$ served as a basis in prospecting for corral sites used by pastoral nomads. Because of the high spatial resolution of the images $(0.6 \mathrm{~m})$, flimsy structures left by mobile societies, typical of the area, have been traced, located and recorded by the remote-sensing methods. Stone-built corrals are

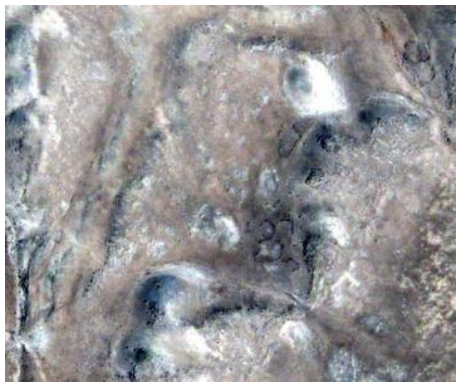

Figure 15. QuickBird image revealing corrals and cairns/tumuli on Jebel Bishri. (C) EurImage.

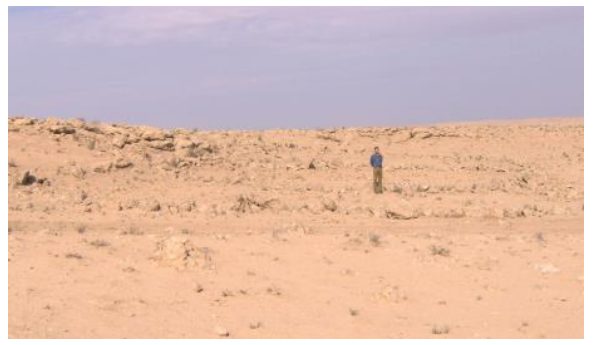

Figure 16. Corrals surveyed on the ground. Photo: M. Lönnqvist (present Silver) 2009.

common nomadic structures in the Near East, and some in Iran and Afghanistan have been made of mud (Cribb, 1991, 96). Corrals form the second commonest archaeological structure type pertaining to pastoralists in the region of Jebel Bishri (Fig. 16), the cairn/tumulus tombs being the most common category of the remains (see Lönnqvist, et al. 2011).

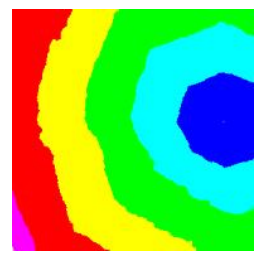

Figure 17. Hiking distance measurements for the corral site F26 on Jebel Bishri using GIS. The analysis executed by M. Törmä 2009.

Hiking distance was studied taking into account the radiant of the grazing area for the pens. Travel time was estimated using Tobler's hiking distance (Fig. 17). More or less one kilometer became the hiking distance to the nearest seasonal water course. (Lönnqvist et al., 2011).

For constructing pastoral landscape models of Jebel Bishri QuickBird data was fused with range-based ASTER-DEM (ASTER Digital Elevation Model) data (Fig. 18). Because of the high spatial resolution the models became very natural-looking. 


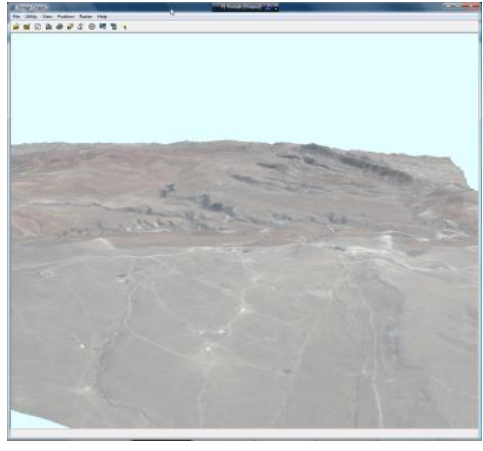

Figure 18. 3D-landscape model of pastoral steppe on Jebel Bishri constructed by fusing QuickBird imagery with ASTER-DEM data. Constructed by M. Törmä 2012.

\section{MIGRATIONS, WAYS OF COMMUNICATION AND TRADE}

There are various ways people come in contact with each other. For mobile people migration is an integral part of their life style if we think about local migration depending on seasonality and interareal migration (Rouse, 1986) caused, for example, by drought or war. However, migrations are hard to trace by remote sensing, and types of spread of cultural features are often followed by spatial comparison to material remains through survey or/and excavation discoveries. However, the tracks such as hollow ways have been identified in the landscape of Syria, and they have been studied by remote sensing using CORONA satellite photographs. These ancient tracks were used by people taking their animals to pastures and fields, but also communicating and trade between settlements (Ur, 2003). On the other hand, we have traced caravan routes by Landsat imagery (Lönnqvist et al., 2011).

Trade was already initiated in the Stone Age, but the means of exchange have changed over time. Obsidian, volcanic glass, that is also present on Jebel Bishri, was acquired from Anatolia, and there is evidence that obsidian was a commodity to be exchanged in prehistory. Flint in the region of Jebel Bishri itself is of very high quality and was used for producing tools and weapons. White ware and pottery start emerging in the Neolithic times and continue to the present-day, and such pieces of vessels were found on Jebel Bishri (Lönnqvist et al., 2011). However, small trade goods are not generally detectable by remote sensing but caravanserai as well as caravan cities, including such as Petra, Palmyra (Silver et al., 2018) and the mentioned Ubar, can be traced.

\section{CONCLUDING REMARKS}

This paper has provided an avenue for studying ancient and more recent mobile people, whether hunter-gatherers or pastoral nomads, and their environments by remote sensing. We have shown which data sources are applicable to particular types of remains in the Near East. Also the environmental questions attached to the livelihood of the people living on desert fringes and steppes have been discussed, and the ways to extract information of the constraints and possibilities. We also wish to highlight the imbalance of World Heritage Sites in view of mobile cultures compared to the sedentary ones and the importance of such cultures in the time scale of the human past.

\section{REFERENCES}

Aldenderfer, M., Maschner, H.D.G. 1996. Anthropology, Space, and Geographic Information Systems. Oxford: Oxford University Press.

Bell, G.L. 1908/ new imp. 1985. Syria: the Desert and the Sown. London: Darf Publishers Ltd.

Bird, D.W. and Bird, R. B. 2005. Evolutionary and Ecological Understanding of the Economics of Desert Societies Comparing the Great Basin USA and the Australian Deserts. Desert Peoples, archaeological perspectives, ed. by Veth, P., Smith, M. and Hiscock, P. Oxford: Blackwells, 81-99.

Bradbury, J. 2009. Beyond a Landscape of Tells: Subsistence, Society and Interaction within Basalt Environs of Homs, Syria. CBRL, Bulletin of the Council for British Research in the Levant 4, 38-41.

Brooks, R. R. and Johannes, D. 1990. Phytoarchaeology. Historical, Ethno- \& Economic Botany Series, Vol. 3. Wilshire: Dioscorides Press.

Burmeister, S. 2000. Archaeology and Migration: Approaches to an Archaeological Proof of Migration. Current Anthropology 41.4, 539-567.

Butzer, K. 1981. Archaeology as Human Ecology. Cambridge: Cambridge University Press.

Cavalli-Sforza, L.L. 1996. The Great Human Diasporas: The History of Diversity and Evolution. Perseus Books.

Chang, C. 2005. The Grass is Greener on the Other Side, in Archaeology and Ethnoarchaeology of Mobility, ed. Seller, F., Greaves, R. and Yu, P.-L, 184-200.

Crassard, R., Barge, O., Bichot, C.-E., Élie, C.-E., Brochier, J. É., Chahoud, J., Chambrade, M.-L., Chataigner, C., Madi, K., Régagnon, E., Seba, H., Vila, E. 2014. Addressing the Desert Kites Phenomenon and Its Global Range Through a Multi-proxy Approach. Journal of Archaeological Method and Theory 22, 1093-1121.

Cribb, R. 1992. Nomads in Archaeology. New Studies in archaeology. Cambridge: Cambridge University Press.

Dietrich, O., Heun, M., Notroff, J., Schmidt, K. And Zarnkow, M. 2012. The role of cult and Feasting in the emergence of Neolithic cimmunities. New evidence from Göbekli Tepe, south-eastern Turkey. Antiquity 86, 674-695.

Heathcote, R.L. 1983. Arid Lands: Their Use and Abuse. Themes in Resource Management. London, New York: Longman.

Lewis, N.N. 1987. Nomads and settlers in Syria and Jordan, 1800-1980. Cambridge: Cambridge University Press. 
Khazanov, A. 1994. $2^{\text {nd }}$ ed. Nomads and the Outside World. Madison: University of Wisconsin Press.

Lem, P. 2017. Finding a Lost City; Fingerprints of Ubar. https:// earthobservatory.nasa.gov. Accessed March 15 ${ }^{\text {th }}, 2019$.

Long-term Landscape Environment and Climate Change Studies: from the Past through to Predictive Models for Future Developments 2012. CBRL 2012, Bulletin of the Council for British Research in the Levant, 7, 60-64.

Lönnqvist, M. 2014. The Emergence of Pastoral Transhumance at Jebel Bishri in Central Syria. Settlement Dynamics and HumanLandscape Interaction in the Dry Steppes of Syria, ed. Morandi Bonacossi, D., Studia Chaburensia I, Vol. 4, 93-109.

Lönnqvist, M. and Stefanakis, E. 2009. GIScience in Archaeology: Ancient Human Traces in Automated Space. The Manual of Geographic Information Systems, ed. Madden, M., Bethesda, Maryland: American Society of Photogrammetry and Remote Sensing, 1221-1259.

Lönnqvist, M. and Törmä, M. 2003. SYGIS-The Finnish Archaeological Project in Syria, The ICOMOS \& ISPRS Committee for Documentation of Cultural Heritage. New Perspectives to Save Cultural Heritage, CIPA 2003, XIXth International Symposium, Antalya, Turkey, The ISPRS International Archives of the Photogrammetry, Remote Sensing and SpatialInformation Sciences Vol. XXXIV-5/C15, 609-614

Lönnqvist, M., Törmä, M., Okkonen, J., Lönnqvist, K., Nuñez, M., Latikka, J. 2007. The Euphrates Channel Changes and Archaeology along Jebel Bishri in Syria. Proceedings of the XXI Symposium, CIPA 2007, Athens, Anticipating the Future of the Cultural past, Vol. 1., ed. Georgopoulos, A., The International Archives of Photogrammetry, Remote Sensing and Spatial Information Sciences, Vol. XXXVI-5/C53, 465-470.

Lönnqvist, M., Törmä, M., Lönnqvist, K., Nuñez, M. 2009.

Site Catchment Analysis Applied to the Pastoral Landscape of Jebel Bishri in Syria Using QuickBird Satellite Imagery and Aster-Dem Data. Proceedings of CIPA 2009, Kyoto, http://cipa.icomos.org/fileadmin/papers/kyoto2009/181pdf

Lönnqvist, M., Törmä, M., Lönnqvist, K., Nuñez, M., Okkonen, J., Stout Whiting, M., Riihiaho, H., Nissinen, M. 2010. Desertification and Ethnoarchaeology: Studying Hazards in the Nomadic Environment of Jebel Bishri in Syria. Proceedings of the 6th International Congress on the Archaeology of the Ancient Near East, May 5th-10th 2008, "Sapienza"- Università di Roma, Vol. 1, Near Eastern Archaeology in the Past, Present and Future: Heritage and Identity, Ethnoarchaeological and Interdisciplinary Approach: Results and Perspectives, Visual Expression and Craft Production in the Definition of Social Relations and Status, ed. by Matthiae, P., Pinnock, F., Nigro, L., Marchetti, N. with the collaboration of L. Romano, Wiesbaden: Harrassowitz Verlag, 369-390.

Lönnqvist, M., Törmä, M., Lönnqvist, K., Nuñez, M. 2011. Jebel Bishri in Focus: Remote sensing, archaeological surveying, mapping and GIS studies of Jebel Bishri in central Syria by the
Finnish project SYGIS, British Archaeological Reports, International Series 2230, Oxford: Archaeopress.

Lönnqvist, M., Törmä, M., Lönnqvist K., Nuñez, M. 2012. Satellite Perspective on Highland-Lowland Human Interaction in Ancient Syria. International Archives of Photogrammetry, Remote Sensing and Spatial Information Sciences, Vol. XXXIX B4, XXII ISPRS Congress 25 August -01 September 2012, ed. Madden, M. and Shortis, M., Melbourne, Australia, 455-460.

Oppenheimer, S. 2004. Out of Eden: The Peopling of the World. London: Constable \& Robinson Ltd.

Richards, J. 1993. Remote Sensing Digital Image Analysis. $2^{\text {nd }}$ ed. Berlin: Springer.

Rouse, I. 1986. Migrations in Prehistory: Inferring Population Movement from Cultural Remains. New Haven, London: Yale University Press.

Schmidt, K. 2012. A Stone Age Sanctuary in South-eastern Anatolia. Berlin: Ex Oriente/Dbusiness.

Silver, M. 2016a. Conservation Techniques in Cultural Heritage. $3 D$ Recording, Documentation and Management of Cultural Heritage, ed. Stylianidis, E., Remondino, F., Dunbeath, Caithness, Scotland, UK: Whittles Publishing, 15-105.

Silver, M. 2016b. Visualising Invisible Nomads. Unpublished paper. World Heritage Strategy Forum. Harvard University, 9th to 22th September, 2016.

Silver, M., Fangi, G., Denker, A. 2018. Reviving Palmyra in Multiple Dimensions. Images, Ruins and Cultural Memory. Caithness, UK: Whittles Publishing.

Silver, K., Silver, M., Törmä, M., Okkonen, J., Okkonen, T. 2017. Applying Satellite Data Sources in the Documentation and Landscape Modelling for Graeco-Roman/Byzantine Fortified Sites in the Tūr Abdin Area, Eastern Turkey. ISPRS Annals of the Photogrammetry, Remote Sensing and Spatial Information Sciences, Vol. IV-2/W2, 2017, 26th International CIPA Symposium 2017, 28 August-01 September 2017, Ottawa, Canada, 251-258.

Ur, J. 2003. CORONA Satellite Photography and Ancient Road Networks: A Northern Mesopotamian Case Study. Antiquity 77, 102-115.

Wendrich, W. and Barnard, H. 2008. The Archaeology of Mobility: Definitions and Research Approaches. The Archaeology of Mobility, Old World and New World Nomadism, Barnard, H. and Wendrich, W., Cotsen Advanced seminars 4, Los Angeles: Cotsen Institute of Archaeology, University of California, 1-21.

Zarins, J. 1992. Archaeological and Chronological Problems within the Greater Southwest Asian Arid Zone, 8500-1850 B.C. Chronologies in Old World Archaeology. Third Edition, Edited by R.W. Ehrich, Vol. I. Chicago and London: The University of Chicago Press, 42-62. 